Text: 254 words

Abstract: 1,680 words

Tables: 3

Figure: 1

\title{
Electroconvulsive therapy for older adult patients with major \\ depressive disorder: a systematic review of randomized controlled trials
}

\section{Running Head: ECT for older depressed patients}

${ }^{1 \#}$ Min Dong, MD,

${ }^{2 \#}$ Xiao-Min Zhu, MD, PhD;

${ }^{3 \#}$ Wei Zheng, MD;

${ }^{4 \# . X i a o-H o n g ~ L i, ~ M D, ~ P h D ~}$

${ }^{5}$ Chee H. Ng, MBBS, MD

${ }^{6,7}$ Gabor S. Ungvari, MD, PhD

${ }^{2 *}$ Yu-Tao Xiang, MD, PhD

1. Unit of Psychiatry, Faculty of Health Sciences, University of Macau, Macao SAR, China;

2. Institute of Mental Health, Suzhou Psychiatric Hospital, The Affiliated Guangji Hospital of Soochow University, Jiangsu, China;

3. The Affiliated Brain Hospital of Guangzhou Medical University (Guangzhou Huiai Hospital), Guangzhou, China;

4. The National Clinical Research Center for Mental Disorders \& Beijing Key Laboratory of Mental Disorders, Beijing Anding Hospital, Capital Medical University, Beijing, China;

5. Department of Psychiatry, University of Melbourne, Melbourne, Victoria, Australia

6. University of Notre Dame Australia / Graylands Hospital, Perth, Australia;

7. Division of Psychiatry, Medical School, University of Western Australia, Perth, Australia

\# These authors contributed equally to the paper.

*Address correspondence to Dr. Yu-Tao Xiang, 3/F, Building E12, Faculty of Health Sciences, University of Macau, Avenida da Universidade, Taipa, Macau SAR, China. Fax: +853-2288-2314;

This is the author manuscript accepted for publication and has undergone full peer review but has not been through the copyediting, typesetting, pagination and proofreading process, which may lead to differences between this version and the Version of Record. Please cite this article as doi: $10.1111 /$ psyg.12359

This article is protected by copyright. All rights reserved. 
Phone: +853-8822-4223; E-mail: xyutly@gmail.com

This article is protected by copyright. All rights reserved. 


\section{ABSTRACT}

Background: Electroconvulsive therapy (ECT) has been widely used in treating older adult patients with major depressive disorder (MDD). The results of randomized controlled trials (RCTs) are mixed. This study systematically examined the efficacy and safety of ECT versus antidepressants (ADs) in older adult patients with MDD.

Methods: Literature search was conducted independently by two reviewers examining the PubMed, Embase, PsycINFO, Cochrane Library, Chinese National Knowledge Infrastructure, Wanfang and SinoMed databases from their inceptions until May 17, 2017. The Cochrane risk of bias and Jadad scale were used to assess the quality of RCTs included in the systematic review.

Results: Five RCTs ( $n=374$; mean age of $66.0-66.4$ years; males: 36.4\%-58.3\%) all conducted in China were identified including 3 RCTs $(n=203)$ with ECT alone and 2 RTCs $(n=171)$ with ECT-ADs co-treatment. In 2 of the 3 RCTs, ECT alone was superior to ADs monotherapy in improving depressive symptoms assessed with the Hamilton Depression Scale (HAMD) and clinical judgment at the conclusion of the course of ECT. Both RCTs of AD-ECT co-treatment showed significant reduction of the HAMD total score at post-ECT compared with ADs monotherapy. The response rate ranged from $80 \%$ to $97.5 \%$ in the ECT groups and $63.4 \%$ to $73.3 \%$ in ADs groups. No group differences were found in terms of adverse reactions (ARs). Only one RCT reported the discontinuation rate without significant group difference.

Conclusions: This systematic review showed that ECT appears to be an 
effective and safe treatment of older adult patients with MDD. Further high quality studies with extended follow-up are warranted.

Key words: older adults, electroconvulsive therapy, major depressive disorder

\section{INTRODUCTION}

Late-life depression is a common psychiatric disorder ${ }^{1}$ which has more complications than early-onset or adult depression. For instance, late-life depression is often associated with more chronic course, worse prognosis, higher recurrence rate, and greater likelihood of cognitive impairment, psychotic symptoms, medical morbidities and mortality. ${ }^{2-5}$ Up to one third of depressed patients do not remit after acute pharmacological treatment, ${ }^{6}$ particularly older patients. ${ }^{7}$ As comorbid physical diseases are common, there is a high likelihood of antidepressant-induced side effects occurring in older adult. ${ }^{8}$ For this reason, electroconvulsive therapy (ECT) is an alternative treatment for late-life depression. ECT yields higher remission rate in middle-aged and older adult patients than younger ones, ${ }^{9-11}$ but the findings have been inconsistent.

ECT is widely used for older MDD patients in many countries. ${ }^{12}$ In a survey $43.6 \%$ of older hospitalized patients with MDD received ECT. ${ }^{13}$ However, the use of ECT in treating psychiatric disorders remains controversial. Some experts argued that ECT could rapidly improve psychiatric symptoms and shorten hospital stay, ${ }^{14}$ but others contended that ECT should be strictly controlled due to the risk of cognitive effects. ${ }^{15}$ Therefore, the efficacy and safety of ECT in late-life depression needs to be examined, with particular attention paid to 
randomized controlled trials (RCTs). The findings of RCTs of ECT in late-life depression conducted have been mixed. The response rates of ECT range from $80 \%$ to $97.5 \%, 16,17$ which is partly due to different patients mixed and study design across studies. Many studies were reported in non-English journals, therefore not readily accessible to the international readership.

For these reasons, this study systematically examined the efficacy and safety of ECT versus antidepressants (ADs) in older adult patients with MDD.

\section{METHODS}

Search strategy and study selection

Both English (PubMed, Embase, PsycINFO and Cochrane Library) and Chinese (Chinese National Knowledge Infrastructure, Wanfang and SinoMed) databases were searched from their inception until May 17, 2017. The following search terms were used: (random*) AND (older adults OR elderly OR aged OR aging) AND (electroconvulsive shock OR electroconvulsive therapy OR ECT OR MECT) AND (depression OR depressive OR depressed). Moreover, reference lists from relevant review were manually searched in order to avoid missing any studies.

\section{Inclusion and exclusion criteria}

Studies that fulfilled the following criteria according to the PICOS strategy of the Preferred Reporting Items for Systematic Reviews and Meta-Analyses (PRISMA) statement ${ }^{18}$ were included in this review: (1) Participants: older patients with MDD defined by respective studies; (2) Intervention: real ECT alone or real ECT 
plus ADs; (3) Comparison: ADs monotherapy or sham ECT plus ADs; (4) Outcomes: primary outcome was the improvement of depressive symptoms as measured by standardized rating scales (such as the Hamilton Depression Scale; HAMD) ${ }^{19}$ or clinical judgement by psychiatrists; secondary outcomes were dropout rate and adverse reactions (ARs); (5) Study design: RCTs with relevant data. Review articles, case series and those without accessible full texts were excluded.

\section{Data extraction}

Two authors (DM and ZXM) independently searched the literature and extracted relevant data. Any disagreement was resolved by a discussion with a third author (ZW).

\section{Quality assessment}

The quality of studies including method of random sequence generation (selection bias), allocation concealment (selection bias), blinding of participants and personnel (performance bias), blinding of outcome assessment (detection bias), incomplete outcome data (attrition bias), selective reporting (reporting bias) and other bias was assessed by the Cochrane risk of bias. ${ }^{20}$ In addition, the Jadad scale ${ }^{21}$ was used to evaluate the quality of studies; the total score $<3$ indicated low quality; otherwise, studies were considered as high quality.

\section{RESULTS}




\section{Literature search}

The flow chart of study is shown in Figure 1. A total of 1,654 potentially relevant studies were identified, but only 5 RCTs, ${ }^{16,17,22-24}$ all conducted in China, which fulfilled the inclusion criteria were analyzed.

\section{Study characteristics}

Table 1 presents the characteristics of the five RCTs involving 374 patients, including 3 RCTs $(n=203)$ with ECT alone and 2 RCTs $(n=171)$ with ADs-ECT co-treatment. The proportion of male patients varied from $36.4 \%$ to $58.3 \%$, the mean age ranged from 66.0 to 66.4 years in the whole sample. The number of ECT sessions ranged from 6 to 12, while the length of the ECT course ranged from 2 to 8 weeks.

The improvement after the treatment with ECT

ECT alone vs. ADs

Of the 3 RCTs comparing ECT alone and ADs, in 2 RCTs ECT alone was superior to ADs improving depressive symptoms assessed with the HAMD ${ }^{24}$ and clinical judgment ${ }^{17}$ at post-ECT assessment (Table 1). Furthermore, the post-ECT response rate (reduction of HAMD total score $>50 \%$ ) was $96.7 \%$ in the ECT group and $73.3 \%$ in the ADs group $(p<0.05)^{24}$ while the corresponding figures were $97.5 \%$ and $63.4 \%(p<0.05)$ in the other study. ${ }^{17}$ However, the third RCT did not find significant improvement in post-ECT depressive symptoms measured with the HAMD. ${ }^{16}$ 
Adjunctive $E C T+A D s$ vs. ADs

Patients in the ECT groups received ECT and ADs concurrently. In one study the post-ECT HAMD total score was reduced significantly in the ECT group compared to the ADs group. ${ }^{22}$ Another study found a significantly higher response rate (85.3\%) in the ECT group than in the AD group (64.9\%) measured with the HAMD. ${ }^{23}$ The discontinuation rate of $17.1 \%$ was reported only in one study ${ }^{23}$ (Table 2).

$\underline{A R S}$

ECT alone vs. ADs

The most common ARs reported in the three studies were memory impairment (19.4\%-30.0\%, 3 RCTs), headache or dizziness (6.7\%-16.1\%, 2 RCTs), nausea or vomiting (9.7\%, 2 RCTs), muscle pain (1 RCTs) in the ECT group, while thirst or dry mouth $(6.7 \%, 3$ RCTs), headache or dizziness $(10.0 \%-20.0 \%, 2$ RCTs), constipation (2 RCTs), nausea or vomiting (13.3\%, 1 RCTs), drowsiness (1 RCTs), insomnia (6.7\%, 1 RCTs), and dysuria (16.7\%, 1 RCTs) in the ADs group (Table 2).

Adjunctive $E C T+A D s$ vs. $A D s$

Patients reported nausea or vomiting (14.7\%, 2 RCTs), muscle pain (1 RCTs), memory impairment (1 RCTs), headache or dizziness (41.2\%, 1 RCTs), thirst or 
dry mouth (14.7\%, 1 RCTs), and sleepiness (8.8\%, 1 RCTs) in the ECT+ADs group, and nausea or vomiting (27\%, 2 RCTs), thirst or dry mouth $(16.2 \%, 2$ RCTs), constipation (1 RCTs), headache or dizziness (10.8\%, 2 RCTs) in the ADs group (Table 2).

Quality assessment

All RCTs mentioned "randomized allocation", while only one detailed its method (Table 3). All RCTs were open label trials and were rated as high risk regarding allocation concealment. Incomplete outcome data were addressed, thus selective reporting were rated as low risk. The mean JADAD score was 2.2 , and its range was from 2 to 3 (Table 1 ).

\section{DISCUSSION}

This was the first systematic review that examined the efficacy and safety of ECT in older adult patients with MDD. The extracted data were not meta-analyzable, therefore only a systematic review was performed.

According to this review, ECT appears to be effective in treating older adults with MDD although its long-term efficacy was not reported. The mechanism of ECT for depression is still unclear. ECT could alter the sensitivity of certain neurotransmitters, including dopamine, serotonin, adrenaline and GABA. ${ }^{25-27}$ Further, the serum level of brain-derived neurotrophic factor (BDNF) was significantly lower in depressed patients than in healthy controls, which could 
increase after ECT. ${ }^{28}$ Because of its effectiveness treating late-life depression, ECT has been considered as the "gold standard" treatment for older adults with antidepressant-resistant depression. ${ }^{29-31}$

A recent review found that the response rate of ECT in late-life depression ranged from $60 \%$ to $80 \%,{ }^{32}$ considerably lower than the figures ( $80 \%$ to $97.5 \%$ ) found in this systematic review. The reason for this discrepancy is not clear. Treatment response to ECT is dependent on a host of factors including the severity of depressive symptoms at baseline and other patient characteristics, such as medical co-morbidity, the mode of delivery of ECT (unilateral vs. bitemporal electrode placement, type of anesthesia, etc.), and assessment instruments. In addition, treatment-resistant depression is common in older patients. ${ }^{33}$ ECT is recommended for antidepressant-resistant patients or who cannot tolerate pharmacotherapy. ${ }^{34}$ Antidepressant-resistant patients had a response rate of up to $71 \%$ to ECT. ${ }^{35}$ However, no RCT in this study included medication-resistant depressed patients.

In terms of safety, 4 studies reported transient memory impairment in the ECT group, with the rate ranging from $19.4 \%$ to $30.0 \%$. Memory impairment is associated with abnormal electrical activities in the hippocampus and the change of memory encode process related to ECT. ${ }^{36-38}$ ECT-induced cognitive impairment is more obvious in the first 3 days after ECT, but working memory, anterograde memory and part of executive functions are significantly improve after 15 days. ${ }^{39}$ The possible reasons for different type and percentage of cognitive changes across studies include comorbidities, such as cardiovascular, 
metabolic and neurodegenerative diseases, different methods of the cognitive assessments and a characteristics of the delivery of ECT. ${ }^{40}$ In this review, nausea and headache were common side effects of ECT, comparable to the rates of $23 \%$ and $48 \%$, respectively, reported earlier. ${ }^{41}$ Thirst or dry mouth were reported in the ADs group of all studies, while sleepiness was only reported in the ECT group in one study. As found previously, ${ }^{42}$ most side effects were transient. ${ }^{16,24}$ The discontinuation rate was reported only in one study ${ }^{16}$ without observing group difference. Apart from one patient who dropped out due to arrhythmia, ${ }^{23}$ no other severe side effects of ECT were reported in any of the studies.

There are several limitations in this review. First, the data of the RCTs were not meta-analyzable due to the small number of studies, the diverse delivery methods and the length of ECT course. Second, further important methodological shortcomings included the lack of blinding and standardized assessment of treatment response and complications that may have reduced the power to detect minor changes. Third, the long-term effect of ECT were not examined. Finally, all RCTs included in the review included only Chinese patients. Studies targeting different ethnic populations are warranted.

In conclusion, this systematic review confirmed that ECT appears to be effective and safe in the treatment of older Chinese adults with MDD. High quality RCTs of extended duration in other settings are warranted.

\section{Competing financial interests}

There is no conflict of financial interest concerning the authors in conducting this 
study and preparing the manuscript.

\section{Acknowledgments}

The study was supported by the University of Macau (SRG2014-00019-FHS; MYRG2015-00230-FHS; MYRG2016-00005-FHS).

\section{Figure legend}

Figure 1. Flowchart for study selection

\section{REFERENCES}

1. Volkert J, Schulz H, Härter M, Wlodarczyk O, Andreas S. The prevalence of mental disorders in older people in Western countries-a meta-analysis. Ageing research reviews 2013; 12: 339-353.

2. Dillon $\mathrm{C}$, Allegri RF, Serrano $\mathrm{CM}$, et al. Late-versus early-onset geriatric depression in a memory research center. Neuropsychiatr Dis Treat 2009; 5: 517. 3. Aziz R, Steffens DC. What are the causes of late-life depression? Psychiatr Clin North Am 2013; 36: 497-516.

4. Shamsi A, Cichon D, Obey J, et al. Pharmacotherapy for late-life depression with psychotic features: A review of literature of randomized control trials. Current Psychiatry Reviews 2010; 6: 219-222.

5. Mitchell AJ, Subramaniam H. Prognosis of depression in old age compared to middle age: a systematic review of comparative studies. Am J Psychiatry 2005; 162: 1588-1601. 
6. Rush AJ, Trivedi MH, Wisniewski SR, et al. Acute and longer-term outcomes in depressed outpatients requiring one or several treatment steps: a STAR* D report. Am J Psychiatry 2006; 163: 1905-1917.

7. Riva-Posse P, Hermida AP, McDonald WM. The role of electroconvulsive and neuromodulation therapies in the treatment of geriatric depression. Psychiatr Clin North Am 2013; 36: 607-630.

8. Katona CL. Psychotropics and drug interactions in the elderly patient. Int J Geriatr Psychiatry 2001; 16.

9. Tew JD, Mulsant BH, Haskett RF, et al. Acute efficacy of ECT in the treatment of major depression in the old-old. The American journal of psychiatry, 1999. http://onlinelibrary.wiley.com/o/cochrane/clcentral/articles/719/CN-00264719/ frame.html

10. Flint AJ, Gagnon N. Effective use of electroconvulsive therapy in late-life depression. Can J Psychiatry 2002; 47: 734-741.

11. Brus O, Cao $Y$, Gustafsson $E$, et al. Self-assessed remission rates after electroconvulsive therapy of depressive disorders. Eur Psychiatry 2017; 45: 154-160.

12. Tang $Y L$, Jiang $W$, Ren $Y P, M a X$, Cotes RO, McDonald WM. Electroconvulsive therapy in China: clinical practice and research on efficacy. J ECT 2012; 28: 206-212.

13. Zhang $X Q$, Wang $Z M$, Pan $Y L$, et al. Use of electroconvulsive therapy in older Chinese psychiatric patients. Int J Geriatr Psychiatry 2015; 30: 851-856.

14. Huang J, Gao YX, Liu DF. Modified electroconvulsive therapy for bipolar 
disorders (in Chinese). Journal of Clinical Psychological Medicine 2010; 20: 57. 15. Chung KF. Electroconvulsive therapy in Hong Kong: rates of use, indications, and outcome. J ECT 2003; 19: 98-102.

16. Wang YY, Ruan YS, Cai YQ. The efficacy and safety assessment of MECT in 60 patients with late-life depression. Journal of Jiujiang University 2012; 27: 76-78. 17. Zhang $X, L i$ YJ, Sun W. Efficacy observation of MECT in the treatment of senile depression. Contemporary Medicine Forum 2014; 221-221,222.

18. Moher D, Liberati A, Tetzlaff J, Altman DG. Preferred reporting items for systematic reviews and meta-analyses: the PRISMA statement. Ann Intern Med 2009; 151: 264-269, w264.

19. Hamilton M. Hamilton depression scale. ECDEU Assessment Manual For Psychopharmacology, Revised Edition Rockville, MD: National Institute of Mental Health 1976; 179-192.

20. Higgins JP, Green S. Cochrane handbook for systematic reviews of interventions: John Wiley \& Sons; 2011.

21. Jadad AR, Moore RA, Carroll D, et al. Assessing the quality of reports of randomized clinical trials: is blinding necessary? Control Clin Trials 1996; 17: $1-12$.

22. Ma L, Wu L, Wu H. Efficacy observation of Escitalopram combined with MECT in senile depression. Medical Journal of Chinese People's Health 2016; 28: 38-39.

23. Jiang $X Q$, Yang $K R$, Zheng $L F$, et al. MECT combined with sertraline in treatment of elderly patients with major depression. Zhejiang Medical Journal 
$2014 ; 1245-1247,1254$.

24. Chen W, Wang YM, Zhang XL. The treatment and care of MECT in patient with late-life depression. Journal of Aerospace Medicine 2013; 24: 1429-1430.

25. Heninger G, Delgado P, Charney D. The revised monoamine theory of depression: a modulatory role for monoamines, based on new findings from monoamine depletion experiments in humans. Pharmacopsychiatry 1996; 29: $2-11$.

26. Esel E, Kose K, Hacimusalar Y, et al. The effects of electroconvulsive therapy on GABAergic function in major depressive patients. J ECT 2008; 24: 224-228. 27. Pfleiderer B, Michael N, Erfurth A, et al. Effective electroconvulsive therapy reverses glutamate/glutamine deficit in the left anterior cingulum of unipolar depressed patients. Psychiatry Research: Neuroimaging 2003; 122: 185-192. 28. Hu Y, Yu X, Yang F, et al. The level of serum brain-derived neurotrophic factor is associated with the therapeutic efficacy of modified electroconvulsive therapy in Chinese patients with depression. J ECT 2010; 26: 121-125.

29. McDonald WM. Neuromodulation Treatments for Geriatric Mood and Cognitive Disorders. Am J Geriatr Psychiatry 2016; 24: 1130-1141.

30. McDonald WM, Weiner RD, Fochtmann LJ, McCall WV. The FDA and ECT. J ECT 2016; 32: 75-77.

31. Kellner CH, Greenberg RM, Murrough JW, Bryson EO, Briggs MC, Pasculli RM. ECT in treatment-resistant depression. Am J Psychiatry 2012; 169: 1238-1244. 32. Kok RM, Reynolds CF, 3rd. Management of Depression in Older Adults: A Review. JAMA 2017; 317: 2114-2122. 
33. Licht-Strunk E, van der Windt DA, Van Marwijk HW, de Haan M, Beekman AT. The prognosis of depression in older patients in general practice and the community. A systematic review. Family practice $2007 ; 24: 168-180$.

34. American Psychiatric Association. The practice of electroconvulsive therapy: recommendations for treatment, training, and privileging. USA, 2008.

35. Folkerts $H$, Michael N, Tölle R, Schonauer K, Mücke S, Schulze-Mönking H. Electroconvulsive therapy vs. paroxetine in treatment-resistant depression-a randomized study. Acta Psychiatr Scand 1997; 96: 334-342.

36. MacPherson RD, Loo CK. Cognitive impairment following electroconvulsive therapy-does the choice of anesthetic agent make a difference? J ECT 2008; 24: $52-56$.

37. Lamont SR, Stanwell BJ, Hill R, Reid IC, Stewart CA. Ketamine pre-treatment dissociates the effects of electroconvulsive stimulation on mossy fibre sprouting and cellular proliferation in the dentate gyrus. Brain Res 2005; 1053: 27-32. 38. Reid IC, Stewart CA. Seizures, memory and synaptic plasticity. Seizure 1997; 6: 351-359.

39. Semkovska M, McLoughlin DM. Objective cognitive performance associated with electroconvulsive therapy for depression: a systematic review and meta-analysis. Biological psychiatry 2010; 68: 568-577.

40. Gardner BK, O'connor DW. A review of the cognitive effects of electroconvulsive therapy in older adults. The journal of ECT $2008 ; \mathbf{2 4 :} 68-80$. 41. Datto CJ. Side effects of electroconvulsive therapy. Depress Anxiety 2000;

12: $130-134$. 
42. Li Y, An FR, Zhu H, et al. Knowledge and Attitudes of Patients and Their Relatives Toward Electroconvulsive Therapy in China. Perspect Psychiatr Care 2016; 52: 248-253.

This article is protected by copyright. All rights reserved. 
Table 1. Summary of studies included in the systematic review

\begin{tabular}{|c|c|c|c|c|c|c|c|c|c|c|}
\hline \begin{tabular}{|c} 
Study \\
(courtry)
\end{tabular} & $\mathbf{N}$ & $\begin{array}{l}\text { Design } \\
\text {-Blinding } \\
\text {-Setting }\end{array}$ & $\begin{array}{l}\text { Participa } \\
\text { nts } \\
\text {-Criteria } \\
\text {-Illness } \\
\text { duration }\end{array}$ & $\begin{array}{l}\text { Sex : } \\
\text { \% of } \\
\text { males in } \\
\text { whole } \\
\text { sample, } \\
\text { ECT and } \\
\text { ADs } \\
\text { groups }\end{array}$ & $\begin{array}{l}\text { Age } \\
\text { (yrs) in } \\
\text { whole } \\
\text { sample, } \\
\text { ECT and } \\
\text { ADs } \\
\text { groups }\end{array}$ & $\begin{array}{l}\text { ECT }{ }^{\text {a }} \text { : sessions (range); } \\
\text { ADs dosages }{ }^{\mathrm{a}} \text { : mg/day } \\
\text { (range); } \\
\text { Number of recruited } \\
\text { patients/analyzed patients } \\
\left(\text { n/n } \mathbf{n}_{\mathrm{A}}\right) ; \\
\text { Analysis: ITT/PP }\end{array}$ & $\begin{array}{c}\text { Trial or } \\
\text { ECT } \\
\text { duration } \\
\text { (wks) }\end{array}$ & $\begin{array}{c}\text { Bilateral } \\
\text { or } \\
\text { unilateral }\end{array}$ & Main findings & $\begin{array}{c}\text { Jadad } \\
\text { score }\end{array}$ \\
\hline \multicolumn{11}{|c|}{ ECT vs. ADs monotherapy } \\
\hline $\begin{array}{l}\text { Zhang } \\
2014 \\
\text { (China) }\end{array}$ & 82 & $\begin{array}{l}\text {-Open label } \\
\text {-Inpatients }\end{array}$ & $\begin{array}{l}-\mathrm{NR} \\
-\mathrm{NR}\end{array}$ & $\begin{array}{c}31 \\
(37.8 \%) ; \\
\text { NR; } \\
\text { NR }\end{array}$ & $\begin{array}{c}\text { 66.0; NR; } \\
\text { NR } \\
(63-79)\end{array}$ & $\begin{array}{l}\text { 1. ECT }(M=N R, R=6-12) ; \\
n / n_{A}=41 / 41 \\
\text { 2. Paroxetine }(M=40 \\
R=40) ; n / n_{A}=41 / 41 ; \\
\text { ITT }\end{array}$ & $\begin{array}{c}\text { NR or } \\
2-4\end{array}$ & NR & $\begin{array}{l}\text { The superiority in the improvement of } \\
\text { post-ECT depressive symptoms and mean } \\
\text { shorter hospitalization in ECT group than in } \\
\text { control group. Response rate: } 97.5 \% \text { in ECT } \\
\text { group vs. } 63.4 \% \text { in ADs group (Rating scale: } \\
\text { NA). }\end{array}$ & 2 \\
\hline $\begin{array}{l}\text { Chen } 2013 \\
\text { (China) }\end{array}$ & 61 & $\begin{array}{l}\text { - Open label } \\
\text {-Inpatients }\end{array}$ & $\begin{array}{l}\text {-CCMD- } \\
3 \\
\text {-NR }\end{array}$ & $\begin{array}{c}28 \\
(45.9 \%) ; \\
\text { NR; } \\
\text { NR }\end{array}$ & $\begin{array}{c}\text { NR; } \\
\text { NR; } \\
\text { NR } \\
(62-75)\end{array}$ & $\begin{array}{l}\text { 1. } \operatorname{ECT}(M=N R, R=6-12) \\
n / n_{A}=31 / 31 \\
\text { 2. } \operatorname{ADs}^{b}(M=N R, R=N R) ; \\
n / n_{A}=30 / 30 \\
\text { ITT }\end{array}$ & $\begin{array}{c}\text { NR or } \\
2-4\end{array}$ & Bilateral & $\begin{array}{l}\text { Rating scale: HAMD. ECT group was } \\
\text { associated with higher response rate than ADs } \\
\text { group. Response rate: } 96.7 \%(30 / 31) \text { in ECT } \\
\text { group vs. } 73.3 \%(22 / 30) \text { in ADs group (HAMD } \\
\text { reduction } \geqslant 50 \%) \text {. }\end{array}$ & 2 \\
\hline $\begin{array}{l}\text { Wang } 2012 \\
\text { (China) }\end{array}$ & 60 & $\begin{array}{l}\text { - Open label } \\
\text {-Inpatients }\end{array}$ & $\begin{array}{l}-\mathrm{ICD}-10 \\
-15 \text { to } 46\end{array}$ & $\begin{array}{c}35 \\
(58.3 \%)\end{array}$ & $\begin{array}{l}66.2 ; \\
66.5\end{array}$ & $\begin{array}{l}\text { 1. } \mathrm{ECT}(\mathrm{M}=\mathrm{NR}, \mathrm{R}=\mathrm{NR}) \\
\mathrm{n} / \mathrm{n}_{\mathrm{A}}=30 / 30\end{array}$ & 8 or 8 & NR & $\begin{array}{l}\text { Rating scale: HAMD. ECT group had } \\
\text { significant improvement in early depressive }\end{array}$ & 2 \\
\hline
\end{tabular}

This article is protected by copyright. All rights reserved. 


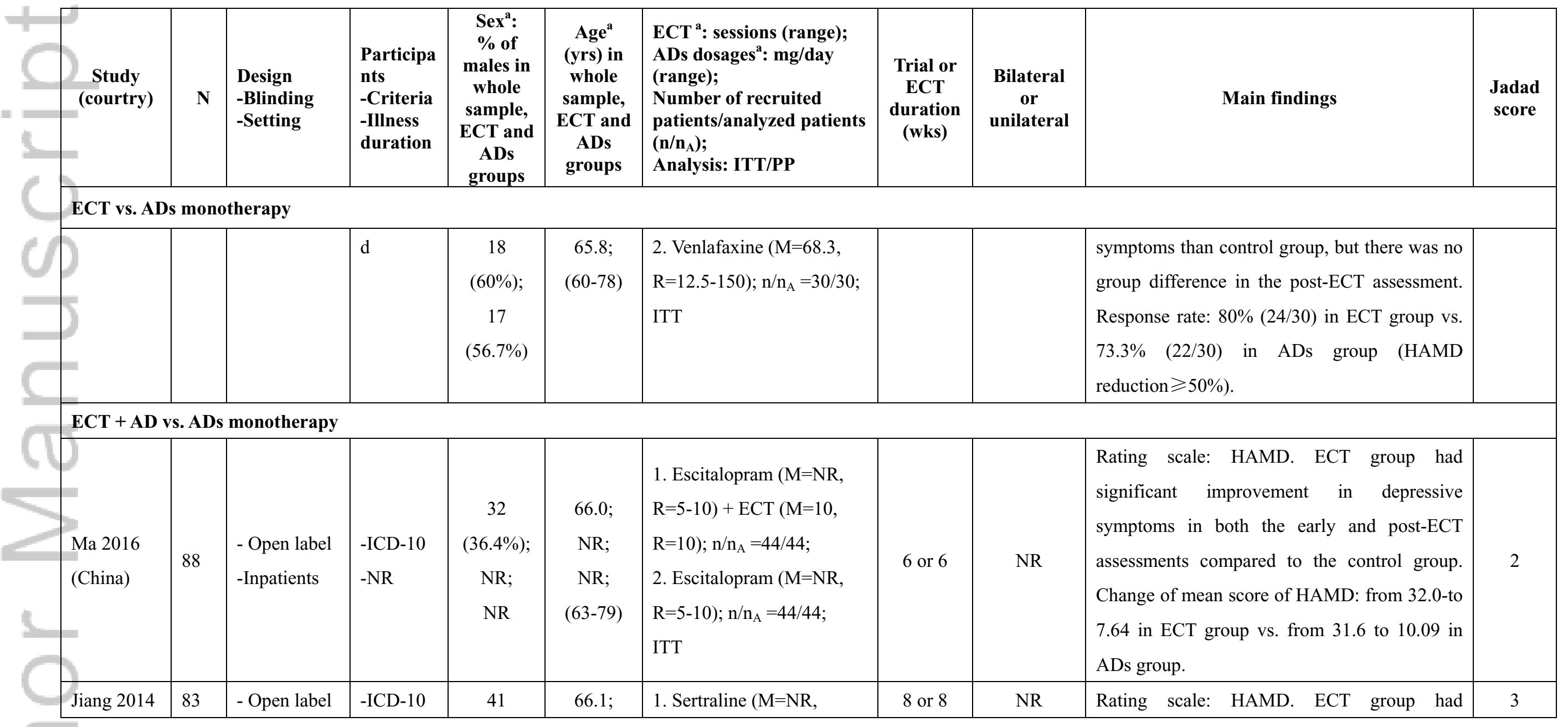

This article is protected by copyright. All rights reserved. 


\begin{tabular}{|c|c|c|c|c|c|c|c|c|c|c|}
\hline $\begin{array}{r}\text { Study } \\
\text { (courtry }\end{array}$ & $\mathbf{N}$ & $\begin{array}{l}\text { Design } \\
\text {-Blinding } \\
\text {-Setting }\end{array}$ & $\begin{array}{l}\text { Participa } \\
\text { nts } \\
\text {-Criteria } \\
\text {-Illness } \\
\text { duration }\end{array}$ & $\begin{array}{l}\text { Sex : } \\
\text { \% of } \\
\text { males in } \\
\text { whole } \\
\text { sample, } \\
\text { ECT and } \\
\text { ADs } \\
\text { groups }\end{array}$ & $\begin{array}{l}\text { Age }^{\mathrm{a}} \\
(\text { yrs) in } \\
\text { whole } \\
\text { sample, } \\
\text { ECT and } \\
\text { ADs } \\
\text { groups }\end{array}$ & $\begin{array}{l}\text { ECT }{ }^{\text {a }} \text { sessions (range); } \\
\text { ADs dosages }{ }^{a}: \text { mg/day } \\
\text { (range); } \\
\text { Number of recruited } \\
\text { patients/analyzed patients } \\
\left(n / n_{\mathrm{A}}\right) ; \\
\text { Analysis: ITT/PP }\end{array}$ & $\begin{array}{c}\text { Trial or } \\
\text { ECT } \\
\text { duration } \\
\text { (wks) }\end{array}$ & $\begin{array}{c}\text { Bilateral } \\
\text { or } \\
\text { unilateral }\end{array}$ & Main findings & $\begin{array}{c}\text { Jadad } \\
\text { score }\end{array}$ \\
\hline \multicolumn{11}{|c|}{ ECT vs. ADs monotherapy } \\
\hline (China) & & $\begin{array}{l}\text {-in- and } \\
\text { outpatients }\end{array}$ & $-\mathrm{NR}$ & $\begin{array}{c}(57.7 \%) \\
19 \\
(50 \%) \\
22 \\
(59.5 \%)\end{array}$ & $\begin{array}{c}65.3 ; \\
66.9 \\
(60-79)\end{array}$ & $\begin{array}{l}\mathrm{R}=50-100)+\mathrm{ECT}(\mathrm{M}=\mathrm{NR} \\
\mathrm{R}=\mathrm{NR}) ; \mathrm{n} / \mathrm{n}_{\mathrm{A}}=41 / 34 \\
\text { 2. Sertraline }(\mathrm{M}=\mathrm{NR} \\
\mathrm{R}=50-100) ; \mathrm{n} / \mathrm{n}_{\mathrm{A}}=42 / 37 \\
\mathrm{PP}\end{array}$ & & & $\begin{array}{l}\text { significant improvement in depressive } \\
\text { symptoms in both the early and post-ECT } \\
\text { assessments compared to the control group. } \\
\text { Response rate: } 85.29 \%(29 / 34) \text { in ECT group } \\
\text { vs. } 64.86 \%(24 / 37) \text { in ADs group (HAMD } \\
\text { reduction } \geqslant 50 \%) \text {. }\end{array}$ & \\
\hline \multicolumn{11}{|c|}{ 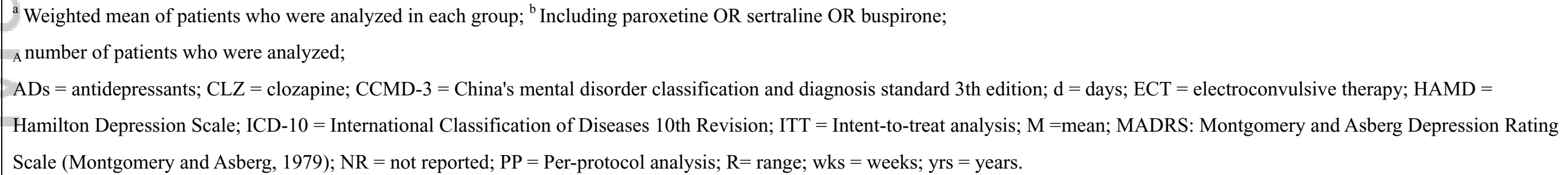 } \\
\hline
\end{tabular}

Table 2. ADs and discontinuation rate

\begin{tabular}{|l|c|c|c|c|c|}
\hline Study & \multicolumn{3}{|c|}{ ECT vs. ADs monotherapy } & \multicolumn{2}{|c|}{ ECT + ADs vs. ADs monotherapy } \\
\hline & Zhang 2014 & Chen 2013 & Wang 2012 & Ma 2016 & Jiang 2014 \\
\hline
\end{tabular}

This article is protected by copyright. All rights reserved. 


\begin{tabular}{|c|c|c|c|c|c|c|c|c|c|c|}
\hline & $\begin{array}{l}\text { ECT } \\
(N=41)\end{array}$ & $\begin{array}{l}\text { ADs } \\
(\mathrm{N}=41)\end{array}$ & $\begin{array}{l}\text { ECT } \\
(\mathrm{N}=31)\end{array}$ & $\begin{array}{l}\text { ADs } \\
(\mathrm{N}=30)\end{array}$ & $\begin{array}{l}\text { ECT } \\
(N=30)\end{array}$ & $\begin{array}{l}\text { ADs } \\
(\mathrm{N}=30)\end{array}$ & $\begin{array}{l}\text { ECT } \\
(N=44)\end{array}$ & $\begin{array}{l}\text { ADs } \\
(\mathrm{N}=44)\end{array}$ & ECT $\quad(N=34)$ & $\begin{array}{l}\text { ADs } \\
(\mathrm{N}=37)\end{array}$ \\
\hline \multicolumn{11}{|l|}{ ARs } \\
\hline All & 24.4 & 26.8 & NR & NR & NR & NR & 24.5 & 26.0 & / & I \\
\hline Nausea/vomiting (n, \%) & NA & / & $3(9.7 \%)$ & / & / & $4(13.3 \%)$ & NA & NA & $5(14.7 \%)$ & $10(27.0 \%)$ \\
\hline Muscle soreness (n, \%) & NA & / & / & / & / & / & NA & / & / & / \\
\hline Memory impairment (n, \%) & NA & / & $6(19.4 \%)$ & / & $9(30.0 \%)$ & / & NA & / & / & / \\
\hline Drowsiness $(n, \%)$ & / & NA & I & / & / & / & I & / & / & / \\
\hline Thirst/dry mouth (n, \%) & I & NA & I & $N A^{a}$ & / & $2(6.7 \%)$ & I & NA & $5(14.7 \%)$ & $6(16.2 \%)$ \\
\hline Headache or dizziness ( $n, \%)$ & / & I & $5(16.1 \%)$ & $6(20.0 \%)$ & $2(6.7 \%)$ & $3(10.0 \%)$ & I & NA & $14^{\mathrm{b}}(41.2 \%)$ & $4(10.8 \%)$ \\
\hline Insomnia (n, \%) & / & / & I & / & / & $2(6.7 \%)$ & I & / & / & / \\
\hline Sleepiness ( $n, \%)$ & / & / & I & / & / & / & / & / & $3(8.8 \%)$ & / \\
\hline Dysuria $(n, \%)$ & / & I & I & $5(16.7 \%)$ & / & / & I & / & / & I \\
\hline Constipation (n, \%) & / & NA & / & $N A^{a}$ & I & / & I & NA & / & I \\
\hline Night sweat (n, \%) & / & I & I & / & I & / & I & / & / & $3(8.1 \%)$ \\
\hline \multicolumn{11}{|l|}{ Discontinuation rate } \\
\hline All causes $(n, \%)$ & / & I & I & I & / & I & I & / & $7(17.1 \%)$ & $5(11.9 \%)$ \\
\hline ARs $(n, \%)$ & / & I & / & / & / & / & I & / & 7 (17.1\%) & $2(4.8 \%)$ \\
\hline Inefficacy $(n, \%)$ & / & I & / & / & / & / & / & / & / & $3(7.1 \%)$ \\
\hline
\end{tabular}

${ }^{a}$ This trial failed to separately report the number of patients with dry mouth and constipation $(n=10)$.

${ }^{b}$ This data were extracted from the total number of patients with headache $(n=6)$ and dizziness $(n=8)$.

This article is protected by copyright. All rights reserved. 
NA: This was reported in the study but the number was not applicable. /: This was not reported in the study. 
Table 3. Cochrane Risk of bias

\begin{tabular}{|c|c|c|c|c|c|c|c|}
\hline & 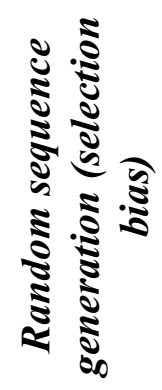 & 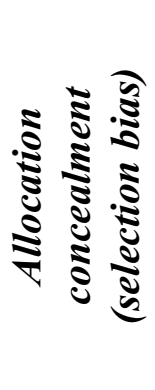 & 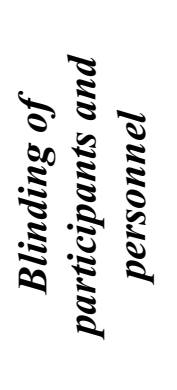 & 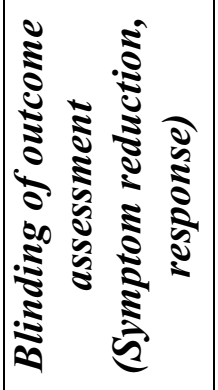 & 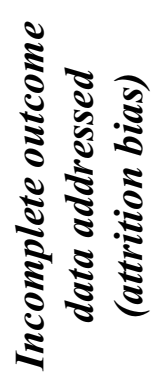 & 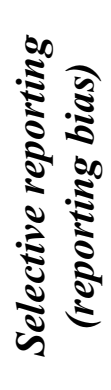 & 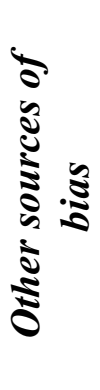 \\
\hline Zhang 2014 & $?$ & - & - & - & + & + & $?$ \\
\hline Chen 2013 & $?$ & - & - & - & + & + & $?$ \\
\hline Wang 2012 & $?$ & - & - & - & + & + & $?$ \\
\hline Ma 2016 & $?$ & - & - & - & + & + & $?$ \\
\hline Jiang 2014 & + & - & - & - & + & + & $?$ \\
\hline
\end{tabular}

+ :Low risk of bias, - : High risk of bias, ? : Unclear risk of bias 


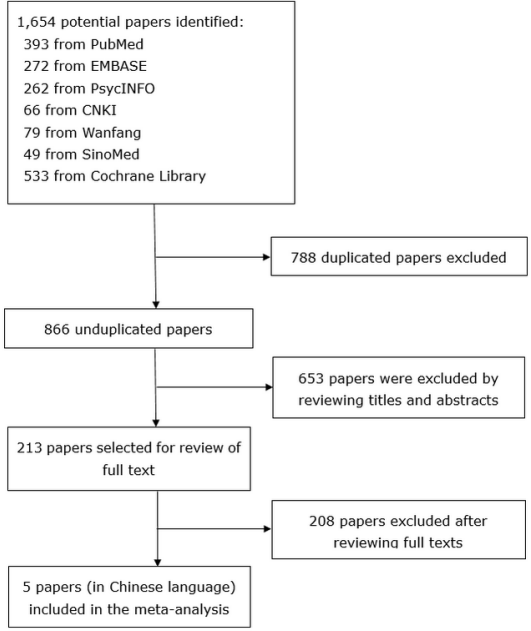

Figure 1.tif

This article is protected by copyright. All rights reserved. 


\section{University Library}

\section{- M M N E R VA A gateway to Melbourne's research publications}

Minerva Access is the Institutional Repository of The University of Melbourne

\section{Author/s:}

Dong, M;Zhu, X-M;Zheng, W;Li, X-H;Ng, CH;Ungvari, GS;Xiang, Y-T

Title:

Electroconvulsive therapy for older adult patients with major depressive disorder: a systematic review of randomized controlled trials

\section{Date:}

2018-11-01

\section{Citation:}

Dong, M., Zhu, X. -M., Zheng, W., Li, X. -H., Ng, C. H., Ungvari, G. S. \& Xiang, Y. -T. (2018). Electroconvulsive therapy for older adult patients with major depressive disorder: a systematic review of randomized controlled trials. PSYCHOGERIATRICS, 18 (6), pp.468-475. https://doi.org/10.1111/psyg.12359.

Persistent Link:

http://hdl.handle.net/11343/284358 